\title{
Some Precautionary Measures to Avoid COVID-19 Spread Among Workers
}

\author{
Rasha Kadhim Mahdi, Sura I.A. Jabuk*, Shaymaa O. H. Al-Mamoori, Noor Saadallah Naji \\ Department of Biology, College of Science, University of Babylon, Babylon, Iraq. \\ * suraihsan@yahoo.com
}

\begin{abstract}
:
Coronavirus Disease 2019 (COVID-19) is a SARS-CoV-2 virus-caused It is critical for every worker to prepare for COVID-19 now to eliminate the impact of COVID-19 epidemic conditions on companies, staff, consumers and the public. Workers must maintain employee social distance activities and monitor the flow of customers; regular and sufficient hand-washing, facilities and surface sanitation for workers; and maintain stay for sick worker's home or go home if they feel ill. As well as the organization should put in place the proceeding safety precautions at all places of work such as public Health Laws and Procedures, reducing the meeting and if applicable join meetings by mobiles, cleaning the workplace always with disinfecting fluids and training the workers on wearing the protective equipment's and avoid the closing contact between.
\end{abstract}

Keywords: Precautionary Measures; COVID-19; Workers.

Crossref doi https://doi.org/10.51345/.v31i1.207.g160 


\section{OVERVIEW:}

Coronavirus Disease 2019 (COVID-19) is a respiratory disease is caused by a virus SARS-CoV-2. This had spread throughout the world to many countries around the world. Because of magnitude of COVID-19 's global effect, infective conditions such as those increasing to a stage of a pandemic could even directly impact all aspects of life, such as transportation, business, and so on.

Preparing for COVID-19 now is critical for other workers to minimize the level of COVID-19 epidemic conditions on companies, employees, consumers and the public. For workers who've already planned an influenza epidemic, COVID-19 can involve updating plans to address new SARS-CoV-2 exposure hazards, exposure sources, transmission routes and other unique characteristics (i.e., compared to pandemic influenza viruses). Employees who've not planned for epidemics of the disease must prepare themselves and their workers as far in advance as possible not to worsen epidemic situations. Lack of planning processes can lead to a sequence with problems as workers try and tackle COVID-19 problems with insufficient resources as well as workers who may not be adequately trained for employment under pandemic conditions that they may need to perform.

\section{Transmissible diseases}

Infectious diseases contribute to transmissible diseases which cause health problems. There are pathogenic agents (pathogens) that cause them. Bacteria and viruses that enter, propagate, or discharge into the body. Toxins cause damage to, and function on, normal body cells. Death can result, in extreme cases. This can spread to infectious agents through a person from an infectious source (- for example a sick person) to an individual by means of various modes of transmission.

\section{The Infection Chain}

A number of main factors for an person to get an infection from spreading contagious diseases such as infectious agents (pathogens), source of infection (reservoir), route of exposure, and susceptible host must be present. This is called the chain of infections.

\section{Whose 'pandemic' is?}

A pandemic is an epidemic affecting hundreds of millions of people around the world, causing a significant proportion of them to become sick. Pandemics occur when a virus turns up with somewhat different characteristics. People have little or no immunity to it, because it is new. Usually there are about 2 or 3 such epidemics every decade. The least recent was in 2009 with the H1N1 virus, widely referred to as 'swine flu'. Worldwide nearly half a million people died. An early epidemic of the same H1N1 virus in 1918 resulted in an estimated 20-40 million worldwide deaths, mainly of people aged 20-45. The outbreak of COVID-19 was confirmed an epidemic by the world health organization as from 11 March.

\section{How is it spreading?}

The primary ways the virus to spread whenever anyone having to carry the virus coughs or sneezes is through exposure. Viruses droplets could even transport up to six meters, making transmission from person to person particularly probable.

Viruses, released from the lungs, can also spread by particles known as aerosols. These can fly further and can stay in the air for hours in 3 and studies show that it lives for up to three days on certain hard surfaces. 


\section{General preconditions}

Workers must maintain employee social distance activities and monitor the flow of customers; regular and sufficient hand-washing, facilities and surface sanitation for workers; and maintain stay for sick worker's home or go home if they feel ill. Workers do need to have clear occupational threat awareness about coronavirus and how best to avoid transmission in the language the employee understands Fact sheets are available at www. Lni.wa.gov / safety / safety / topics / coronavirus for particular industries such as foodstuffs, agriculture and construction.

\section{SPECIFIC MEASURES TO MITIGATE COVID-19 FROM SPREADING IN THE PLACE OF WORK}

A low-cost measure below would aid prevent the spreading of diseases in your workplace, such as colds, flu and other infectious diseases, and will secure your customers, suppliers and workers. Workers should start doing these stuff now, even though COVID-19 has not arrived in the places where they work. They will minimize the already lost workdays due to sickness, either help slow COVID-19 spreading if it reaches one of the places of work.

\section{WORKER COMPETENCIES}

The Company is requesting each of our workers to assist with our efforts in prevention while at work. Everyone has to play their part in minimizing the spreading of COVID-19 at our jobsites. The Company has developed various housekeeping, social distance, and other best practices at our job sites as set out below. All employees should follow these. In relation, workers are likely to disclose to their managers or supervisors if they are exhibiting signs or symptoms of COVID-19, as mentioned over. Please tell your supervisor or supervisor if you have a particular question about this Project or COVID19. If they are unable to answer the question, please contact [Manager or Supervisor Title].

\section{PROTECTIVE STEPS AT THE WORK SITE}

The organization has put in place the proceeding safety precautions at all places of work.

\section{1-Public Health Laws and Procedures}

- $\quad$ Any worker / entrepreneur / visitor exhibiting COVID-19 signs will be ordered to leave the work site and return back home.

- $\quad$ Safety meetings should be, if possible by mobile. If in-person safety meetings are held, attendance will be gathered orally and each individual will be signed by the foreman / superintendent. Attendance will not be monitored by mobile devices or passed-around sign-in sheets. Stop participating in groups of more than 10 people at all in-person safety sessions, and the participants will stay at least six (6) feet apart.

- Workers shall avoid physical contact with others and, where possible, guide others (coworkers / contractors / visitors) to maximize their private boundaries to at least six ( 6) feet. When work vehicles are being used, just required workers must join the vehicles and all workers should maintain social distance while inside the vehicles.

\section{2- Workers accessibility}

Employers will want to determine the motivation of the staff and their desire to return to work. Some staff may be enthusiastic about going back to work Whilst others might be more hesitant. Employees 
may as well as must be decide whether workers remain at a position It is subjected to other limitations, including such curfews at night, which can affect their availability for other shifts. Business owners will also must be determine if, at this time, workers whom had recently relocated your residence can move to the workplace or whether accommodations are suitable. Employers can also identify how to support workers who have COVID-19 care responsibilities, like taking care of kids whom schools were closing. Workers may also have the right to depart for purposes relating to COVID-19, including childcare.

\section{3-Needing or preventing attendance of individual}

Employers need to be prepared to react to workers who want to return to a worksite, and may not be able to go back as well as feel extremely uneasy with doing so. Employers also should recognize how and when to reply back to workers who've been interested in returning to the workforce and whose jobs may not end up making someone to a major focus to come back through individual.

\section{- Workers at High Risk}

Employers would also have to deal with workers who, may be at higher risk if they sign COVID-19. The CDC has made recommendations for individuals at greater risk for severe COVID-19 disease, like "older people and people of any age with major underlying health issues. The White House Guidance recommends that "all insecure persons" retain shelter-in-place during the first two phases of return-towork, and states that household members with disabled residents will be mindful of the need to return to work. "There should be appropriate reactions to separate vulnerable people.

"This guideline also urges workers to take strong consideration of special arrangements for vulnerable people. Workers will also take into consideration the conditions and restrictions set out in the ADA when determining whether to provide accommodation to high-risk staff. Extra information on the ADA and COVID-19 can be found in our $\mathrm{m}$, including housing for certain high-risk individuals' memorandum, "EEOC Releases Updated Employers Guidance Concerning ADA-Compliant Practices throughout the COVID-19 Crisis "

\section{- Elderly Workers}

A certain worker is simply not forced to give accommodation to older employees merely because they are at higher risk of serious illness if they contract COVID-19, employers may also consider offering such employees accommodation.

\section{- Pregnant Workers}

While "some pregnancy-related medical problems can often be ADA disorders," and thus cause privileges for accommodation with ADA, Pregnancy itself is not considered an ADA disability Because employers are not allowed to give a benefit to a pregnant employer due to the potentially higher unknown risks associated with COVID-19.

\section{4-Company precaution}

Specific organizational strategies for controlling and handling. For an appropriate and effective handling of the epidemiological position, the competent authorities have imposed an epidemiological emergency of COVID-19. Therefore, organizational safety and mitigation measures are aimed at minimizing the likelihood of exposure to SARS-CoV-2; steps must be taken to avoid new infections or even the transmission of the virus where it already exists. 
It is therefore advantageous for companies in which various people come and go during the day to reduce the entry of visitors strictly to the minimum and also limit access to all topics, including employees. We would also exclude people with obvious flu-like symptoms, and workers who could participate in the survey. In the case of traveling workers, they will not be able to fly in countries In socalled red areas vulnerable to SARS-CoV-2; companies must carry out a surveillance measure of effective monitoring of people who have had close contact with people infected by the disease COVID19 , and the obligation of those who come from places at risk of epidemiology to engage with the prevention department of the skilled healthcare organization, in order to enable a potential evaluation of the contractual residence with positive monitoring.

\section{5-Environmental Practice}

The environmental measures are designed to reduce the transmission of SARS-CoV-2 infection Individuals touching affected subjects, items, equipment or contaminated objects on ambient surfaces.

Even when no disinfectants are expressly reported to be effective on SARS-CoV-2, with virus Commonly, detergents \& disinfectants inactivate similar biochemical and physical properties in use in hospitals; which assures minimal and moderate disinfection after disinfection of the manufacturer Guidelines and technical data sheets on dilution, contact period and handling.

Different research has revealed how coronaviruses, such as the responsible viruses, are For SARS and MERS, low humidity and low temperature optimum conditions will persist, for On inanimate surfaces in all living quarters, in particular toilets, change rooms, for up to 9 days, Canteens, rooms with vendors, smoking areas and multi-person oceans. At the same point, there is proof that the abovementioned viruses are ecologically important. Inactivated by appropriate sanitization procedures including disinfectant use on the basis of Sodium hypochlorite $(0.1 \%-0.5 \%)$, ethanol $(62 \%-71 \%)$ or hydrogen peroxide $(0.5 \%)$ for an acceptable touch time, ensuring good ventilation of the closed rooms. Hence remarkable protocols of cleaning and sanitization Suitable disinfectants / disinfectants must be adopted.

\section{6- Personal precautions}

\section{- Distancing from society}

Social distances are an essential means of reducing the risk of Coronavirus which spreads among people when they work. Worker discussions will help you define where social issues are This will require careful thought and consideration to distinguish ourselves.

Social distancing is critical in preventing the spread of communicable diseases such as COVID-19 (coronavirus) among workers. Through coughing, sneezing and near contact, COVID-19 will spread. Employers should advise workers to avoid closing contact among them while minimizing close contact with others, reducing the chances of virus catching and spreading.

\section{- Regular purification and disinfection}

Routine washing and disinfection is an important factor for increased risk of exposure to COVID-19. Simple daily soap and water purification alone can decrease the chance of contamination, which is a required step before you clean dirty surfaces. Surfaces regularly reached by several individuals, such as door handles, chairs, telephones, light switches and faucets, must be washed and disinfected at least daily. Depending on the level of use more frequent cleaning and disinfection may be necessary. For 
example, all surfaces and products should be cleaned and disinfected in public places, such as shopping carts and keypads for point of sale.

Try selecting another disinfectant if your first option is in shortages. Make sure there is ample supply of gloves and appropriate personal protective equipment (PPE) depending on the mark, the volume of substance to be applied and the size of the surface you handle.

Worker washing, sanitizing and hygiene procedures Workplaces are some of the key ways of making sure employees are Secure working during coronavirus outbreak. Taking staff into conversations about when and where Cleaning will ensure that you have assessed high contact correctly Areas and consider how you're going to manage those.

- $\quad$ Using Personal Protective Equipment (PPE)

- Interim guidelines for individual job teams and your employees have planned PPE costumes for specific work types that the staff should do. Total:

- $\quad$ The PPE will be chosen based on the findings of a risk evaluation of an employer and basic job duties of the workers.

- Workers will usually use a single pair of nitrile test gloves when using disposable gloves. If they get ripped or clearly tainted with blood or body fluids change gloves.

- $\quad$ - Use eye safety goggles or face shields. Personal eyeglasses are not regarded as sufficient eye protection.

- If workers need respirators, they must be used as part of a robust respiratory protection system that meets the OSHA Respiratory Protection Standard (29 CFR 1910.134) criteria, including medical evaluations, suit testing and training.

- $\quad$ Please wash both hands often with soap for at least 20 seconds upon removing your PPE, if necessary. Make sure that manual hygiene facilities (e.g. alcohol-dependent sink or hand rubbing) were also easily and accurately available at the point of using it (e.g., in or adjacent to the removal area of the PPE).

\section{7-Training workers}

Education among all employees with sufficiently possible occupational exposure to SARS-CoV-2 (as illustrated in this document) on the sources of virus exposure, the hazards associated with that exposure, and appropriate workplace procedures in place to prevent or reduce the risk of exposure. Training will include information about how to diagnose criminals or perpetrators of COVID-19 or other infectious diseases, and how to distinguish cases as well. The employee shall be given education at no cost and during normal working hours.

Staff requiring PPE training, including when to use PPE; what PPE is required; how to properly donate (put on), use and doff (take off) PPE; how to properly dispose of or clean, inspect for injury and maintain PPE; and the PPE limitations The related specifications include PPE (29 CFR1910.132); Eye and Face Safety (29 CFR 1910.133) Standards on hand protection (29 CFR 1910.138), and in respiratory protection (29 CFR 1910.134). A variety of training videos about respiratory safety are available on the OSHA website. 


\section{REFERENCES}

World Health Organization-Western Pacific Region. Practical Guidelines for Infection Control in Health Care Facilities. (2003) Retrieved February 21, 2005, from http://www.wpro.who.int/sars/docs/practicalguidelines/default.asp

Lai CC, Shih TP, Ko WC, Tang HJ, Hsueh PR. Severe acute respiratory syndrome coronavirus 2 (SARS-CoV-2) and corona virus disease-2019 (COVID-19): the epidemic and the challenges. Int J Antimicrob Agent. 2020:105924. Doi: 10.1016/j.jjantimicag.2020.105924.

Thomas Z. Misinformation on coronavirus causing 'infodemic'. https://www.bbc.com/news/technology-51497800 (Accessed 09 March 2020)

Selvaraj SA, Lee KE, Harrell M, Ivanov I, Allegranzi B. Infection Rates and Risk Factors for Infection Among Health Workers During Ebola and Marburg Virus Outbreaks: A Systematic Review. J Infect Dis. 2018;218(suppl_5): S679-S689

Cereda D, Tirani M, Rovida F, Demicheli V, Ajelli M, Poletti P, et al. The early phase of the COVID19 outbreak in Lombardy, Italy 2020. Available from: https://arxiv.org/abs/2003.09320v1.

Bhagavathula AS, Aldhaleei WA, Rahmani J, Mahabadi A, Bandari DK. Novel Coronavirus (COVID19) Knowledge and Perceptions: A Survey on Healthcare workers 2020.

Cirrincione L, Plescia F, Ledda C, Rapisarda V, Martorana D, Moldovan RE, et al. COVID-19 Pandemic: Prevention and Protection Measures to Be Adopted at the Workplace n.d.:1-18.

Zhang M, Zhou M, Tang F, Wang Y, Nie H, Zhang L, et al. Knowledge, attitude, and practice regarding COVID-19 among healthcare workers in Henan, China. J Hosp Infect 2020; 105:183-7. doi: 10.1016/j.jhin.2020.04.012.

Zivich PN, Gancz AS, Aiello AE. Effect of hand hygiene on infectious diseases in the office workplace: a systematic review. Am J Infect Control 2017; 46:448-55. https.//doi.org/10.1016/j.ajic.2017.10.006

Yong SEF, Anderson DE, Wei WE, et al. Connecting clusters of COVID-19: an epidemiological and serological investigation. Lancet Infect Dis 2020. Published online April 21, 2020. doi: https://doi.org/10.1016/S1473-3099(20)30273-5

Dong Y, Mo X, Hu Y, et al. Epidemiological characteristics of 2143 pediatric patients with 2019 coronavirus disease in China. Pediatrics 2020 e20200702. doi:10.1542/peds.2020-0702

European Centre for Disease Prevention and Control (ECDC). Event background COVID-19 [cited $20201 \mathrm{March}$. Available from: https://www.ecdc.europa.eu/en/novel-coronavirus/eventbackground-2019.

See generally U.S. CENTERS FOR DISEASE CONTROL AND PREVENTION, Coronavirus Disease 2019 (COVID-19) Interim Guidance for Businesses and Employers, March 21, 2020, https://www.cdc.gov/coronavirus/2019-ncov/community/guidance-business-response.html (last visited April 22, 2020).

European Centre for Disease Prevention and Control (ECDC). Novel coronavirus disease 2019 (COVID-19) pandemic: increased transmission in the EU/EEA and the UK - sixth update 12 March 2020. Stockholm: ECDC; 2020. Available from: https://www.ecdc.europa.eu/sites/default/files/documents/RRA-sixth-update-Outbreak-ofnovel-coronavirus-disease-2019-COVID-19.pdf

World Health Organization (WHO). Coronavirus disease (COVID-19) outbreak [cited $20201 \mathrm{March}$ ]. Available from: https://www.who.int/emergencies/diseases/novel-coronavirus-2019. 
European Centre for Disease Prevention and Control (ECDC). Event background COVID-19 [cited $20201 \mathrm{March}$. Available from: https://www.ecdc.europa.eu/en/novel-coronavirus/eventbackground-2019.

European Centre for Disease Prevention and Control (ECDC). Personal protective equipment (PPE) needs in healthcare settings for the care of patients with suspected or confirmed novel coronavirus $\quad 2020 . \quad$ Available from: https://www.ecdc.europa.eu/sites/default/files/documents/novel-coronavirus-personalprotective-equipment-needs-healthcare-settings.pdf.

Smith JD, MacDougall CC, Johnstone J, Copes RA, Schwartz B, Garber GE. Effectiveness of N95 respirators versus surgical masks in protecting health care workers from acute respiratory infection: a systematic review and meta-analysis. Canadian Medical Association Journal. 2016: cmaj.150835.

European Centre for Disease Prevention and Control (ECDC). Public health management of persons, including healthcare workers, having had contact with COVID-19 cases in the European Union 2020 [March 1, 2020]. Available from: https://www.ecdc.europa.eu/en/publicationsdata/public-health-management-persons-including-health-care-workers-having-had-contact.

European Centre for Disease Prevention and Control (ECDC). COVID-19 2020 [cited $20201 \mathrm{March}$ ]. Available from: https://www.ecdc.europa.eu/en/novel-coronavirus-china. 